\title{
Durchschneidung der Ciliarnerven bei anhaltender Neuralgie eines amaurotischen Auges.
}

\author{
Von \\ Dr. H. Snellen.
}

Herr B. wurde am 15. Jannar 1851 beim Fechten durch einen Fleuretstich verletzt. Die Waffe hatte mit bedeutender Kraft die Maske durchbohrt, und war ohne zu brechen durch das untere Augenlid längs dem Infraorbitalrande tief in die rechte Augenhöhle gedrungen. Nach dem Herausziehen soll das Fleuret ungefähr eine Hand breit mit Blut bedeckt gewesen sein. - Patient fiel sofort bewusstlos hin. Die Blutung war sehr be. dentend, kaum stillbar und dauerte bis zum Abend fort. - Ungefähr 2 Stunden lang blieb Patient ohne Besinnung liegen, dann zeigte es sich, dass seine linke Seite gefühllos, das linke Bein gelahmt, Geruchs- und Gehörssinn derselben Seite gestört waren. Nachdem die Schwellung der Lider abgenommen hatte, erwies sich das rechte Auge als vollkommen blind und blieb schmerzhaft. Ausserdem klagte Patient über ein drückendes Gefibl im Kopfe.

Ein halbes Jahr später, zumal nach Gebrauch von Seebädern, besserte sich der Allgemeinzustand und stellte

จ. Graefe's Archiv fúr Ophtindunologie $x \mathrm{LX}, 1$. 
sich die Function des linken Beins wieder vollkommen her, dagegen blieb die Gefühllosigkeit von Arm und Bein, sowie der Mangel von Geruch und Gehör linkerseits und die Blindheit des rechten Auges.

Im Jahre 1864 consultirte mich Patient wegen heftiger Empfindlichkeit seines amaurotischen Auges. Der geringste Druck, ja selbst leichtes Kneipen der Augenlider verursachte ibm wnerträgliche Schmerzen. Ich constatirte nun, dass die Schmerzhaftigkeit sich auf eine scharf umschriebene Stelle am obern äussern Ciliarrande beschränkte. Entzündungserscheinungen waren keine vorhanden; Lichtperception fehlte vollkommen. Die $\mathrm{Pu}-$ pille hatte dieselbe Weite, wie die des andern Auges, war aber nicht kreisrund, sondern ein wenig nach oben verzogen, erweiterte sich aber auf Atropin vollkommen. Die Papilla nervi optici war total weiss; die Retinalgefässe normal. - Der Bulbus schien nicht hart, jedoch liess sich der heftigen Empfindlichkeit wegen der intraoculare Druck nicht genau bestimmen. Das andere Auge war emmetropisch and ganz normal.

Durch Einträufeln von Atropin und Morphin schien die Schmerzhaftigkeit etwas abzunehmen, aber im Ganzen blieb doch der Zustand derselbe. - Im Spätsommer 71 stellte sich Patient wieder bei mir ein. Eine Reise ins Ausland, die er zu seiner Zerstreuung unternommen, hatte ihren Zweck ganz verfehlt. Die Schmerzhaftigkeit und Empfindlichkeit auf Druck hatten eher zu, als abgenommen, und ausserdem hatte sich ein fortwährendes Gefühl von Druck und Spannung in der Stirn hinzugesellt. Das Gesicht hat einen schmerzlichen Ausuruck, die Augen sind matt, der rechte Mundwinkel ist nach oben gezogen, das rechte Auge divergirt. Im Uebrigen ist der Zustand derselbe geblieben. Die Gefühllosigkeit der linken Extremitaeten hat sich vicht verändert, während Bewegung und Gang keinerlei Störung zeigen. Die Hirnfunctionen 
sind in jeder Beziehung normal, dagegen ist das linke Ohr vollkommen taub, und der Geruchssinn linkerseits herabgesetzt.

Die Exstirpatio bulbi, von welcher bereits früher die Rede gewesen war, wollte Patient aus Rücksicht für seine gesellschaftliche Stellung, wo immer möglich, vermeiden. Ich schlug darum die Durchschneidung der Ciliarnerven vor, was denn auch mit dem besten Erfolge geschah. Die Operation wurde am 22. October 71 in folgender Weise vorgenommen. Nachdem Patient chloroformirt war, machte ich längs dem obern Rande des Rectus extermus einen Conjunctivalschnitt von vorn nach hinten, und eröffnete auf dieselbe Weise auch die Tenonsche Kapsel.

Dann trennte ich die Sehne des Externus subconjunctival von der Selera ab, einerseits um den Strabismus zu corrigiren, andrerseits um auf diese Weise leichter an die Hinterseite des Bulbus gelangen zu können. Hernach suchte ich erst mit einer krummen Scheere, die ich geschlossen einführte, den Opticus auf und fand ihn, da ein Assistent das Auge stark nach innen drehte, nicht direct nach hinten laufend, sondern mehr als eine kleine Erhabenheit auf der Sclerotica. So zufühlend, schnitt ich nun, die Scheere immer fest auf die Sclera drückend, in kleinen Schnitten bis auf den Opticus ein. In diesem Augenblicke trat eine Blutung ein, wahrscheinlich aus durchschnittenen Ciliargefässen. Mit Recht gab ich mich nun der Hoffnung hin, damit auch die Ciliarnerven getrennt zu haben. Die Conjunctiva warde mit 3 Näthen geschlossen, mit deren vordersten ich, um einer allzu starken Reaction des Abducens vorzubeugen, auch den obern Rand von dessen Sehne fasste.

Die Heilung erfolgte ganz regelmässig; nur an der 
vordersten Nath entstand in den ersten Tagen eine geringe Schwellung, welche aber bald abnahm.

Nach der eigentlichen Narcose schlief Patient moch 2 Stunden lang, und erwachte dann mit heftigen Schmerzen, die aber nur einige Augenblicke anhieiten, um dann nie wieder aufzutreten.

Die Untersuchung ergab, dass die Empfindlichkeit auf Druck total gewichen, ja an ihre Stelle sogar vollkommene Anaesthesie getreten war.

Zwischen Rectus externus, und superior war die Conjunctiva bulbi für leichten Druck mit einem Papierstreifen ganz unempfindlich. Das Gebiet der Anaesthesie blieb nach oben und unten scharf begrenzt, während der anliegende Quadrant der Cornea auch verminderte Sensibilität zeigte. Der intraoculare Druck dieses Auges stand jetzt deutlich unter dem des andern. Die Pupille ist gleich weit, wie früher, und erweitert sich auf Atropin vollkommen gut. Der Stand der Augen ist sehr befriedigend. Mit der Schmerzhaftigkeit des Auges ist auch der Stirnkopfschmerz gänzlich verschwunden, und die Veränderung im Gesichtsausdrucke seit dem Aufhören der Schmerzen ist sebr auffallend.

Es unterliegt keinem Zweifel, dass der Fleuretstich von unten nach oben durch die Orbita bis in die Schädelhöhle gedrungen war. Die intracranielle Blutung hat die halbseitige Lähmung und Gefühllosigkeit der Extremitäten, sowie die Taubheit und die Störung des Geruchssinnes veranlasst. Die Amaurose und Atrophie des Sehnerven wird wohl auf Verletzung von weiter hinten gelegenen Nervenfasern beruhen. Was die Schmerzhaftigkeit im Ciliargebiete betrifft, so findet sich ihre Ursache jedenfalls in Narbenbildung an der Hinterseite des Bulbus.

Die Durchschneidung der Ciliarnerven erfüllte ihren Zweck vollkommen, und die ungestörte Circulation der 
Retinalgefässe war ein Beweis dafür, dass dabei der Opticus intact geblieben war.

Vom physiologischen Standpunkt aus scheint es bemerkenswerth, dass die Hornhaut, trotz der gänzlichen Gefihliosigkeit eines ihrer Quadranten doch vollkommen durchsichtig und gesund blieb, und es spricht auch diese Beobachtung wieder gegen die Vorstellung eines tropischen Einflusses des Nervus trigeminus auf die Cornea*).

*) Vergl. Dr. H. Snellen. De invloed der zenuwen op de ontsteking, proefondervindelijk getoetst. Utrecht. 1857. 